\title{
Pengaruh Gaya Kepemimpinan Transformasional dan Budaya Organisasi Terhadap Organizational Citizenship Behavior melalui Komitmen Organisasi
}

\author{
Rohmat Khoirul Anam1, Dani Rizana ${ }^{2}$ \\ 1,2Universitas Putra Bangsa \\ anamrohmatkhoirul@gmail.com ${ }^{1}$
}

\section{ARTICLE INFO}

Article History:

Received: June $19^{\text {th }} 2021$

Accepted: June 21st 2021

Published: June $28^{\text {th }} 2021$

Keywords:

Transformational Leadership

Style, Organizational

Culture, Organizational

Commitment

Organizational Citizenship

Behavior

\begin{abstract}
This study aims to examine the effect of transformational leadership style and organizational culture on organizational citizenship behavior through organizational commitment as an intervening variable. The sampling method used was simple random sampling, that is, the sample was taken randomly without paying attention to the strata in the population. Respondents in this study were 63 employees of UPTD Waste Water and Garbage Management in the Eastern Region of the Perkim LH Office of Kebumen Regency. This research used descriptive analysis method and statistical analysis which carried out validity test, reliability test, multicollinearity test, heteroscedasticity test, normality test, correlation test, determination coefficient test, $\mathrm{t}$ test, path analysis, and single test. Testing in the $t$ test shows that transformational leadership style has a positive and significant effect on organizational commitment to employees of UPTD Pengelolaan air Limbah dan Sampah Wilayah Timur Dinas Perkim LH Kabupaten Kebumen, organizational culture has a positive and significant effect on organizational commitment, transformational leadership style has no effect on organizational citizenship. behavior, organizational culture has a positive and significant effect on organizational citizenship behavior, organizational commitment has a positive and significant effect on organizational citizenship behavior, organizational commitment can mediate transformational leadership styles and organizational citizenship behavior, and organizational commitment can mediate organizational culture and organizational citizenship behavior.
\end{abstract}

\section{Pendahuluan}

Kualitas sumber daya manusia di dalam perusahaan dapat dilihat tidak hanya dari seberapa banyak para anggota mampu berkontribusi dan mampu menyelesaikan semua tugas tugasnya dengan baik, akan tetapi dapat dilihat seberapa banyak para anggota memiliki inisiatif tersendiri dalam menyelesaikan pekerjaan lainnya diluar dari job description. Menurut Stephen Robins (dalam Anna Suzana, 2017: 43) elemen penting yang perlu diperhatikan dalam organisasi adalah perilaku diluar aturan formal organisasi (extra-role ). 
Salah satu perilaku extra role biasa disebut perilaku Organizational Citizenship Behaviour (OCB).

Robbins dan Judge (2015) menyatakan bahwa " Organization Citizenship Behavior adalah perilaku kebebasan menentukan yang bukan bagian dari persyaratan pekerjaan formal pekerja, tetapi berkontribusi pada lingkungan psikologis dan sosial tempat kerja". Jadi, bisa dikatakan bahwa OCB merupakan kontribusi individu yang melebihi tuntutan peran di tempat kerja yang tidak berkaitan langsung dengan sistem reward dan dapat meningkatkan fungsi afektif organisasi.

William \& Anderson (1991) membagi OCB menjadi dua kategori, yaitu OCB-O dan OCB-I. OCB-O adalah perilaku yang memberikan manfaat bagi organisasi secara umum. Contohnya adalah dengan hadir di tempat kerja lebih awal dan mentaati peraturan-peraturan informal yang ada untuk memelihara ketertiban. OCB-I merupakan perilaku-perilaku yang secara tidak langsung juga memberikan kontribusi kepada organisasi, misalnya dengan memabantu rekan kerja yang tidak masuk kerja dengan membantu menyelesaikan pekerjaannya, dan mempunyai perhatian personal kepada karyawan lain. Sehingga dapat disimpulkan bahwa OCB-O adalah perilaku yang memberikan manfaat bagi organisasi secara umum. Sementara OCB-I adalah perilaku yang secara langsung memberi manfaat bagi individu dan secara tidak langsung juga memberikan kontribusi terhadap organisasi. Kedua perilaku tersebut akan meningkatkan fungsi keorganisasian dan berjalan melebihi jangkauan deskripsi pekerjaan yang resmi. Sehingga penting bagi individu di dalam organisasi untuk memiliki perilaku OCB-O dan juga OCB- O.

Mariman Darto dalam karya tulis ilmiahnya tahun 2014 yang berjudul " Peran Organizational Citizenship Behavior Dalam Peningkatan Kinerja Individu Di Sektor Publik : Sebuah Analisis Teoritis Dan Impiris" mengatakan bahwa dalam era reformasi birokrasi sebagimana saat ini sedang dijalankan diberbagai instansi pemerintahan, peran OCB dianggap vital dan sangat menentukan performance organisasi. Fokus utama organisasi sektor publik adalah memberikan pelayanan kepada masyarakat. Tentunya dalam memberikan pelayanan tersebut harus efektif, dan salah satu cara mewujudkannya adalah dengan menerapkan perilaku OCB dilingkungan kerja organisasi.

UPTD Pengelolaan Air Limbah Dan Sampah wilayah Timur Dinas Perumahan, Kawasan Permukiman dan Lingkungan Hidup Kabupaten Kebumen adalah bidang yang difokuskan melaksanakan kegiatan dinas yang bersifat teknis operasional dalam pelaksanaan kebersihan kota berupa pengelolaan air limbah dan sampah dengan wilayah kerja mencakup Kebumen Kota, Kecamatan Kutowinangun, dan Kecamatan Prembun. Dalam hal pembagian tugas kerja lapangan di UPTD Pengelolaan Air Limbah Dan Sampah wilayah Timur sendiri terbagi menjadi empat bagian yaitu bagian pramu kebersihan, driver, penyapuan dan petugas IPLT. Keempat bagian ini saling berkaitan dalam pelaksanaan pekerjaan, ditambah lagi dengan beban kerja yang besar mengharuskan mereka untuk saling bekerja sama dalam menyelesaikan pekerjaan. Tentunya perilaku OCB sangat diperlukan dalam kondisi seperti ini guna menyelesaikan pekerjaan secara efektif dan sesuai target.

Berdasarkan observasi dan hasil wawancara yang telah dilakukan dengan kepala UPTD diketahui bahwa ada fenomena yang mengindikasikan perilaku OCB yang baik dari para pegawai. Pegawai UPTD Pengelolaan Air Limbah Dan Sampah wilayah Timur Dinas Perkim LH saling membantu antar bagian walaupun diluar jobdesk yg sudah ditentukan, dengan 
kesadaran diri menolong rekan kerja yang mengalami hambatan kerja, menyampingkan keinginan pribadi demi pekerjaan, ketika pekerjaan sedang menumpuk dengan senang hati bersedia overtime, dan juga dalam melakukan pekerjaan sesuai prosedur dan selalu berusaha memberikan pelayanan yang terbaik.

Menurut Seders (dalam Nugraha, 2018) meningkatnya perilaku OCB dipengaruhi oleh dua faktor utama, yaitu faktor yang berasal dari dalam diri karyawan (internal) seperti komitmen, rasa puas, kompetensi, sikap positif, dan sebagainya. Sedangkan faktor yang kedua berasal dari luar karyawan (eksternal) seperti sistem manajemen, kepeminpinan, budaya perusahaan (organisasi).

Dari hasil observasi dan wawancara, faktor-faktor yang mempengaruhi OCB pegawai UPTD Pengelolaan Air Limbah Dan Sampah wilayah Timur Dinas Perkim LH yang pertama yaitu gaya kepemimpinan transformasional. Pemimpin yang menerapkan jenis kepemimpinan transformational akan cenderung memacu para pengikutnya untuk menghasilkan pekerjaan melebihi dari apa yang diharapkan, yaitu dengan cara mengubah visi, menjadi contoh, memberi dukungan, serta merangsang keinginan untuk berubah kearah yang lebih baik. kepala UPTD sebagai pimpinan kerja selalu memberikan motivasi dan dukungan baik materil maupun non materil terhadap kualitas kerja bawahannya. Kepala UPTD juga sangat komunikatif dan membaur dengan bawahannya serta menjadi inspirasi tersendiri bagi bawahannya. Sikap dan perilaku yang dicerminkan pimpinan kerja tersebut mempengaruhi para bawahannya untuk selalu berusaha menyelesaikan tugas yang diberikan dengan baik serta berusaha menjaga eksistensi organisasi dalam memberikan pelayanan yang maksimal kepada masyarakat.

UPTD Pengelolaan air Limbah Dan Sampah Wilayah timur Dinas Perkim LH mengharuskan para pegawainya untuk memperioritaskan melakukan pekerjaan berdasarkan tim bukan individu sehingga memicu kepedulian individu terhadap rekan kerja. UPTD juga mengharuskan para pegawainya untuk selalu melakukan inovasi dan berani mengambil resiko, detail dan tepat sasaran disetiap pekerjaannya. Hal ini menjadi budaya organisasi yang berlaku di lingkungan kerja dan kemudian juga mempengaruhi perilaku OCB yang baik dari para pegawai.

Sikap pimpinan yang menjadi role model bagi anggota organisasi dan didukung dengan budaya organisasi yang baik dapat memunculkan energi positif berupa rasa nyaman dalam melakukan pekerjaan dan rasa memiliki terhadap organisasi. Selanjutnya rasa nyaman dan loyal akan membentuk komitmen dari para pegawai terhadap organisasi sebelum memunculkan perilaku OCB. Anggota organisasi yang mempunyai komitmen tinggi terhadap organisasi cenderung akan berusaha memberikan kinerja melebihi yang diharapkan organisasi. Hal ini dibuktikan salah satunya dari sikap profesioanl dan dedikasi yang ditampilkan para pegawai meskipun hari kerja full tujuh hari kerja.

\section{Kajian Teori dan Telaah Literatur}

\section{Organizational Citizenship Behavior}

Robbins dan Timothy (2015) menyatakan bahwa organizational citizenship behavior (OCB) adalah Perilaku bersedia melakukan pekerjaan yang tidak ada dalam deskripsi pekerjaan serta berkontribusi pada lingkungan psikologis dan sosial tempat kerja. Pendapat lain dari 
Ahdiyana (dalam I Putu Satya Nugraha dan I Gusti Ayu Dewi Adnyani, 2018) mengataka bahwa OCB adalah perilaku yang melebihi kewajiban formal (ekstra role) yang tidak berhubungan dengan kompensasi langsung. Artinya, seseorang yang memiliki OCB tinggi rela tidak dibayar dalam bentuk uang atau bonus tertentu, namun lebih kepada perilaku sosial dari masing-masing individu. . Menurut Organ (2006) dalam Doni Juni Priansa ( 2018:248) OCB terdiri dari lima dimensi yang dapat diukur yaitu altruism, coutesy, sportmanship, civic virtue, conscientiousness.

\section{Komitmen Organisasi}

Menurut Robbins (2006) komitmen organisasi adalah suatu keadaan dimana seorang karyawan memihak pada organisasi dan tujuan tujuannya, serta berniat memelihara keanggotaannya itu. Summers dan Actio (dalam Edy Sutrisno, 2010) berpendapat bahwa komitmen organisasi berhubungan dengan tingkat keterlibatan psikologis anggota terhadap organisasi. Keterlibatan psikologis ini akan tercermin pada tingkat aktivitas seseorang tersebut dalam suatu organisasi dan untuk kepentingan organisasi. . Penilaian komitmen organisasi pada penelitian ini dibatasi pada identifikasi komitmen yang dikemukakan oleh Mayer dan Allen (dalam Edy Sutrisno, 2010) yaitu affective commitment, continuance commitment, dan normative commitment.

\section{Gaya Kepemimpinan Transformasional}

Robbins dan Judge (2015) menyatakan bahwa Pemimpin transformasional adalah pemimpin yang menginspirasi para pengikutnya untuk melampaui kepentingan diri mereka sendiri dan yang berkemampuan untuk memiliki pengaruh secara mendalam dan luar biasa terhadap pengikutnya. Seorang pemimpin yang mempunyai gaya kepemimpinan transformasional akan menjadi sosok inspirator bagi bawahannya. Pemimpin menjadi role model bagi bawahannya dalam bertindak, berperilaku, dan dalam melaksanakan tanggung jawab pekerjaan. Bass dan Avolio (dalam Yusnar Lubis, Bambang hermanto, Emron Edison, 2018) mengusulkan empat dimensi dalam kadar kepemimpinan transformasional seseorang, yaitu ideallized influence, inspirational motivation, intellectual stimulation, dan individualized consideration.

\section{Budaya Organisasi}

Terdapat banyak pengertian mengenai budaya organisasi. Salah satunya dikemukakan oleh Stephen P. Robbin (dalam Badeni, 2014: 223) bahwa budaya organisasi mengacu kepada suatu sistem makna bersama yang dianut oleh para anggota organisasi yang membedakan organisasi tersebut dengan organisasi lain. Budaya antar satu organisasi dengan organisasi lainnya tentunya berbeda, sehingga budaya tersebut menjadi identitas dan ciri dari organisasi. Sebagaimana penjelasan mengenai budaya organisasi yang dikemukakan Lunerberg \& Ornstein (dalam I Putu Satya Nugraha, 2018) menyatakan bahwa budaya organisasi adalah semua keyakinan, perasaan, perilaku dan simbol simbol yang mencirikan suatu organisasi. Menurut P. Robbin (dalam Badeni, 2014) bahwa budaya organisasi memiliki tujuh esensi karakteristik, yaitu inovatif and risk tasking, attention to detail, outcome orietation, people orientation, agressiveness, dan stability. 


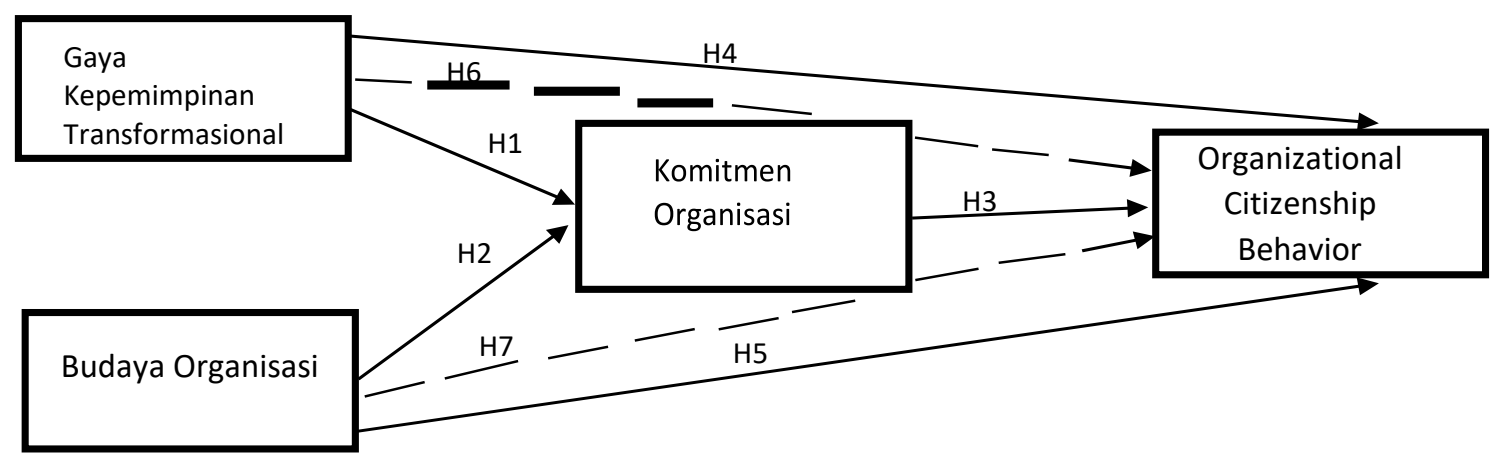

Gambar 1. Model Penelitian

$\mathrm{H}_{1}$ :Gaya kepemimpinan transformasional berpengaruh terhadap komitmen organisasi

$\mathrm{H}_{2}$ :Budaya organisasi berpengaruh terhadap komitmen organisasi

$\mathrm{H}_{3}$ :Komitmen organisasional berpengaruh terhadap organizational citizenship behavior

$\mathrm{H}_{4}$ :Gaya kepemimpinan transformasional berpengaruh terhadap organizational citizenship behavior

$\mathrm{H}_{5}$ :Budaya organisasi berpengaruh terhadap organizational citizenship behavior

$\mathrm{H}_{6}$ :Gaya kepemimpinan transformasional berpengaruh terhadap organizational citizenship behavior melalui komitmen organisasi

$\mathrm{H}_{7}$ :Budaya organisasi berpengaruh terhadap organizational citizenship behavior (OCB) melalui komitmen organisasi.

\section{Metode Penelitian}

Rancangan penelitian ini menggunakan pengujian hipotesis dan penelitian ini menggunakan jenis penelitian kuantitatif. Populasi pada penelitian ini adalah pegawai UPTD Pengelolaan air Limbah dan Simpah Wilayah Timur Dinas Perkim LH Kabupaten Kebumen yang berjumlah 182 orang. Dalam penelitian ini penulis mempersempit populasi dengan menghitung ukuran sampel menggunakan teknik Slovin.

Teknik pengmpulan data yang dilakukan dengan cara : (1) Menyebar langsung kuisioner langsung kepada para pegawai UPTD Pengelolaan Air Limbah dan Sampah Wilayah Timur, (2) wawancara, (3) Studi Pustaka. Instrumen dalam penelitian ini dilakukan dengan menggunakan kuisioner yang ditujukan untuk memperoleh jawaban dari responden. Alat bantu pengolahan data menggunakan SPSs for windows. Teknik analisis data dilakukan dengan dua cara yaitu analisis deskriptif dan analisis statistika. Analisis data secara statistika meliputi : (1) Uji Validitas dan Reliabilitas, (2) Uji Asumsi Klasik, (3) Uji Hipotesis, (4) Analisis Korelasi, (5) Analisis Jalur, (6) Uji Sobel.

\section{Hasil dan Pembahasan}

\section{Uji Validitas}

Suatu kuisioner dinyatakan valid apabila pertanyaan dalam kuisioner tersebut dapat menggambarkan sesuatu yang akan diukur oleh kuisioner tersebut. Alat ukur atau butir kuesioner dinyatakan valid apabila nilai corrected item total correlation (r-hitung) adalah lebih besar bila dibandingkan dengan rtabel dengan tingkat signifikan lebih kecil dari 0,05 
Tabel 1. Hasil Uji Validitas

\begin{tabular}{lccc}
\hline \multicolumn{1}{c}{ Variabel } & Butir & Sign & Status \\
\hline Gaya Kepemimpinan & 8 & Signifikan & Valid \\
Transformasional & 7 & Signifikan & Valid \\
Budaya Organisasi & 6 & Signifikan & Valid \\
Komitmen Organisasi & 10 & Signifikan & Valid \\
Organizational Citizenship Behavior &
\end{tabular}

Sumber: Data Primer Diolah, 2021

Hasil uji validitas seluruh pernyataan yang digunaka dalam variabel Gaya Kepemimpinan Transformasional, Budaya Organisasi, Komitmen Organisasi, dan Organizational Citizenship Behavior dinyatakan valid.

\section{Uji Reliabilitas}

Suatu kuesioner dikatakan reliable atau handal jika jawaban seseorang terhadap pertanyaan adalah konsisten atau stabil dari waktu ke waktu. Pengukuran relibilitas dapat dilakukan dengan one shot dan kemudian hasilnya dibandingkan dengan pertanyaan lain atau mengukur korelasi antar jawaban pertanyaan. Alat untuk mengukur reliabilitas adalah Cronbach Alpha.

Analisis terhadap hasil uji reliabilitas pada penelitian ini dengan menggunakan bantuan programisasi komputer dengan program SPSS 25.0 for windows yang mengacu pada rumus Alpha Cronbach dengan kriteria pengujian uji realibilitas (Ghozali, 2009):

1. Jika Alpha Cronbach $>0,60$ atau $60 \%$, maka butir atau variabel tersebut reliable

2. Jika Alpha Cronbarch < 0,60 atau $60 \%$, maka variabel tersebut tidak reliabel.

Tabel 2. Hasil Uji Reliabilitas

\begin{tabular}{clccc}
\hline No & \multicolumn{1}{c}{ Variabel } & Conbach's Alpha & R Kritis & Keterangan \\
\hline \multirow{2}{*}{$\begin{array}{l}\text { Gaya Kepemimpinan } \\
2\end{array}$} & Transformasional & 0,728 & 0,60 & Reliabel \\
3 & Budaya Organisasi & 0,738 & 0,60 & Reliabel \\
& Komitmen Organisasi & 0,709 & 0,60 & Reliabel \\
& Organizational Citizenship & & & \\
4 & Behavior & 0,718 & 0,60 & Reliabel \\
\hline
\end{tabular}

Sumber : Data Primer Diolah, 2021

Berdasarkan tabel 5, hasil uji validitas pada instrument variabel social media marketing menunjukan bahwa nilai korelasi pada kolom rtabel 0,197 dengan tingkat signifikansi kurang dari 0,05 sehingga dapat disimpulakn bahwa semua butir pernyataan dinyatakan valid. 


\section{Uji Multikolinearitas}

Tabel 3. Hasil Uji Multikolinieritas Sub Struktural I

\begin{tabular}{llcc}
\hline & & \multicolumn{2}{c}{ Colinierity Statistics } \\
\hline No & \multicolumn{1}{c}{ Variabel bebas } & Tolerance & VIF \\
\hline \multirow{2}{*}{$\begin{array}{l}\text { Gaya Kepemimpinan } \\
\text { Transformasional }\end{array}$} & 0,575 & 1,74 \\
2 & Budaya Organisasi & 0,575 & 1,74 \\
\hline
\end{tabular}

Sumber : Data Primer Diolah, 2021

Tabel 4. Hasil Uji Multikolinieritas Sub Struktural II

\begin{tabular}{clcc}
\hline & & \multicolumn{2}{c}{ Colinierity Statistics } \\
\hline No & \multicolumn{1}{c}{ Variabel bebas } & Tolerance & VIF \\
\hline \multirow{2}{*}{1} & Gaya Kepemimpinan & 0,512 & 1,955 \\
2 & Transformasional & 0,433 & 2,308 \\
3 & Kudaya Organisasi & 0,447 & 2,238 \\
Sumber: Data Primer Diolah, 2021 & &
\end{tabular}

Berdasarkan tabel 3 dan 4 di atas dapat diketahui bahwa nilai tolerance lebih besar dari 0,10 dan nilai VIF kurang dari 10, sehingga model regresi tidak terjadi multikolineritas dan dapat dipakai dalam penelitian ini.

\section{Uji Heteroskedastisitas}

Pengujian ini dilakukan untuk menguji apakah dalam sebuah model regresi terjadi ketidaksamaan varian dan residua disuatu pengamatan ke pengamatan yang lain. Hasil analisis uji heteroskedastisitas diperoleh sebagai berikut:

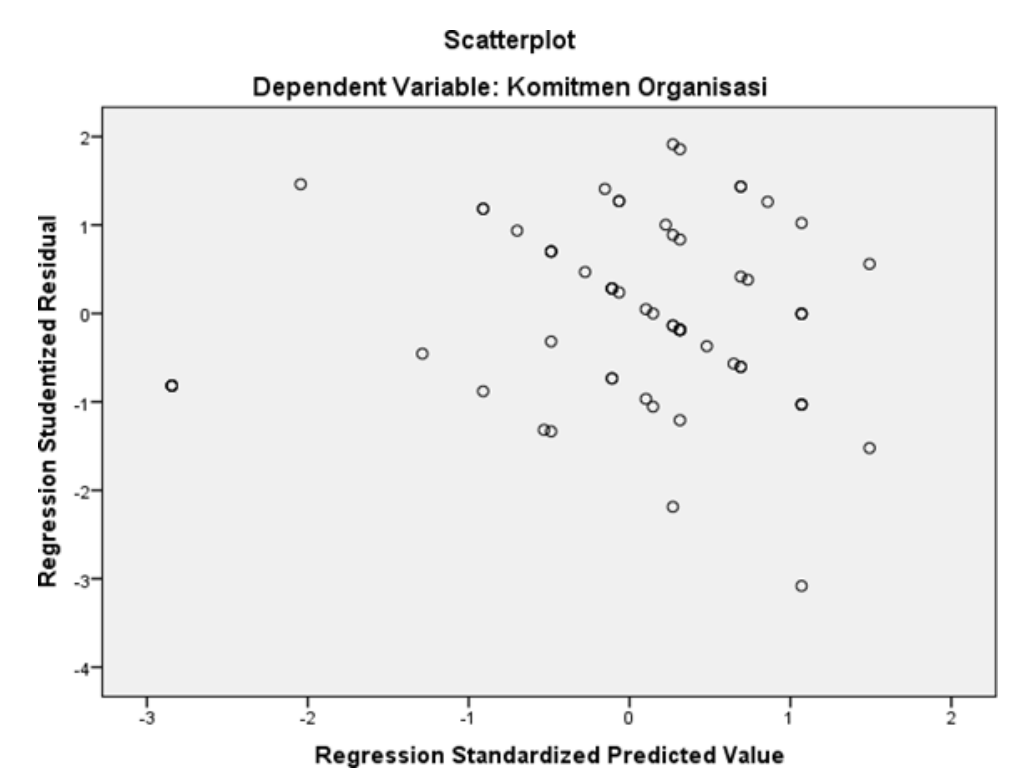

Gambar 2 Hasil Uji Heteroskedastisitas Subtruktural I

Sumber: Data primer diolah, 2021 
Scatterplot

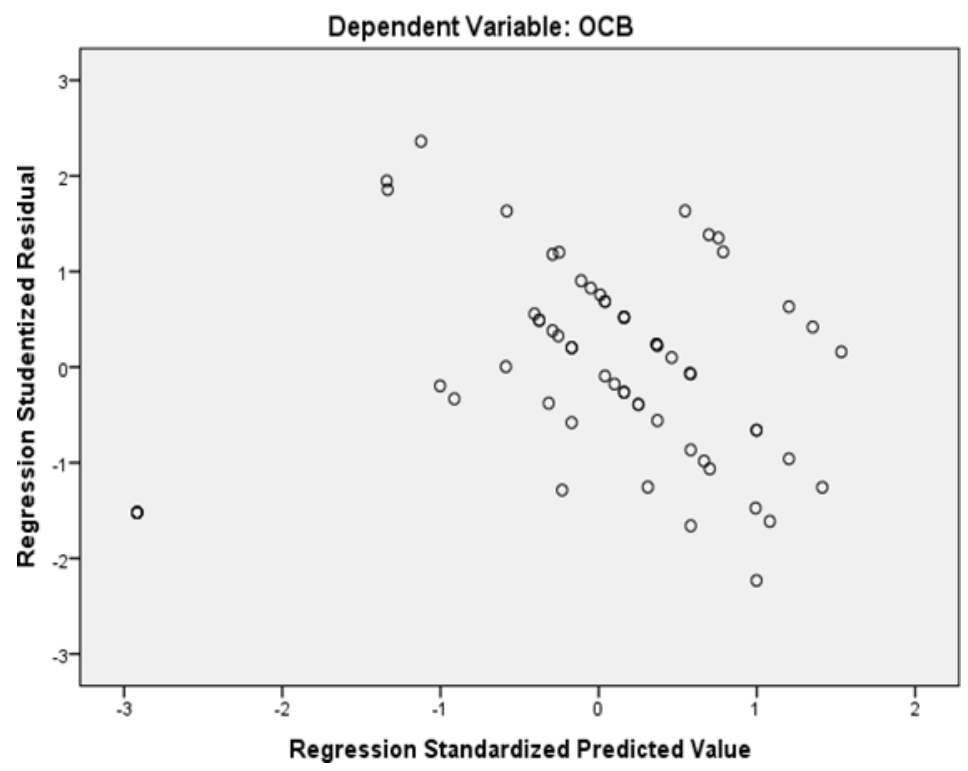

Gambar 3 Hasil Uji Heteroskedastisitas Subtruktural II Sumber: Data primer diolah, 2021

Berdasarkan gambar 2 dan 3 di atas, menunjukan bahwa bulatan-bulatan kecil tidak memiliki pola tertentu, seperti titik-titik atau bulatan yang membentuk suatu pola tertentu yang teratur (bergelombang, melebar, kemudian menyempit) dan tidak ada pola yang jelas sehingga dapat disimpulkan tidak ada gejala heteroskedastisitas model regresi dalam penelitian ini.

\section{Uji Normalitas}

Uji normalitas bertujuan untuk menguji apakah sebuah model regresi, variable residual memiliki distribusi normal. Hasil analisis uji normalitas diperoleh sebagai berikut:

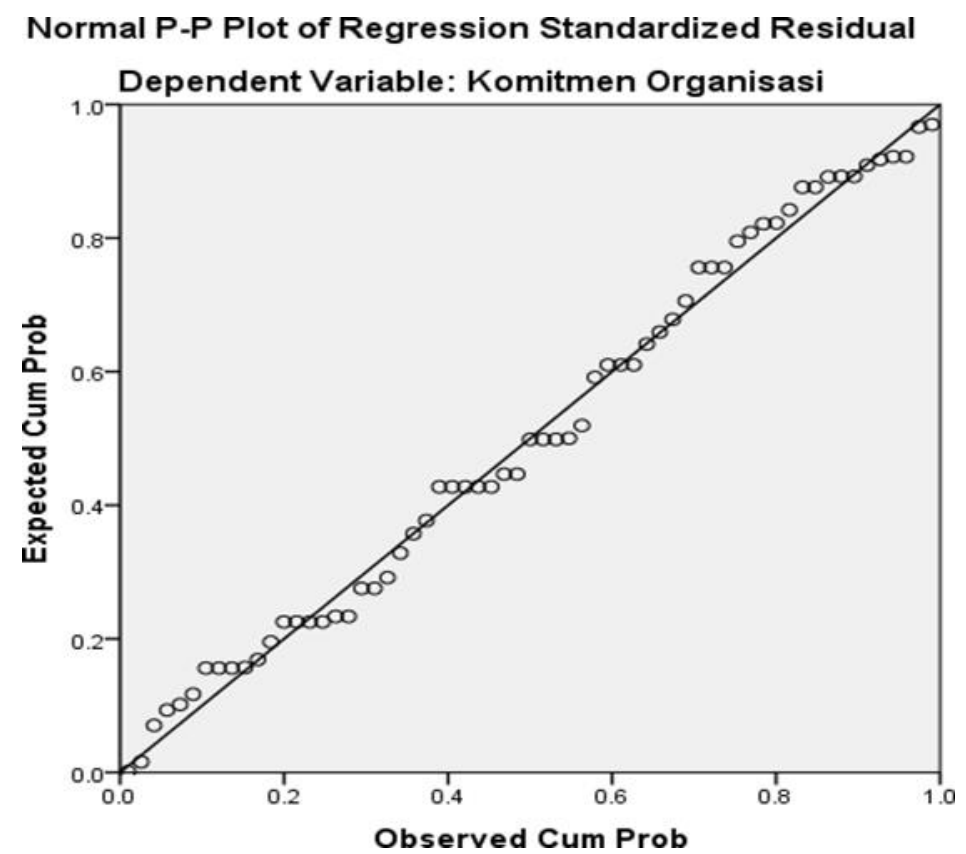

Gambar 4 Hasil Uji Normalitas Subtruktural I

Sumber: Data primer diolah, 2021 


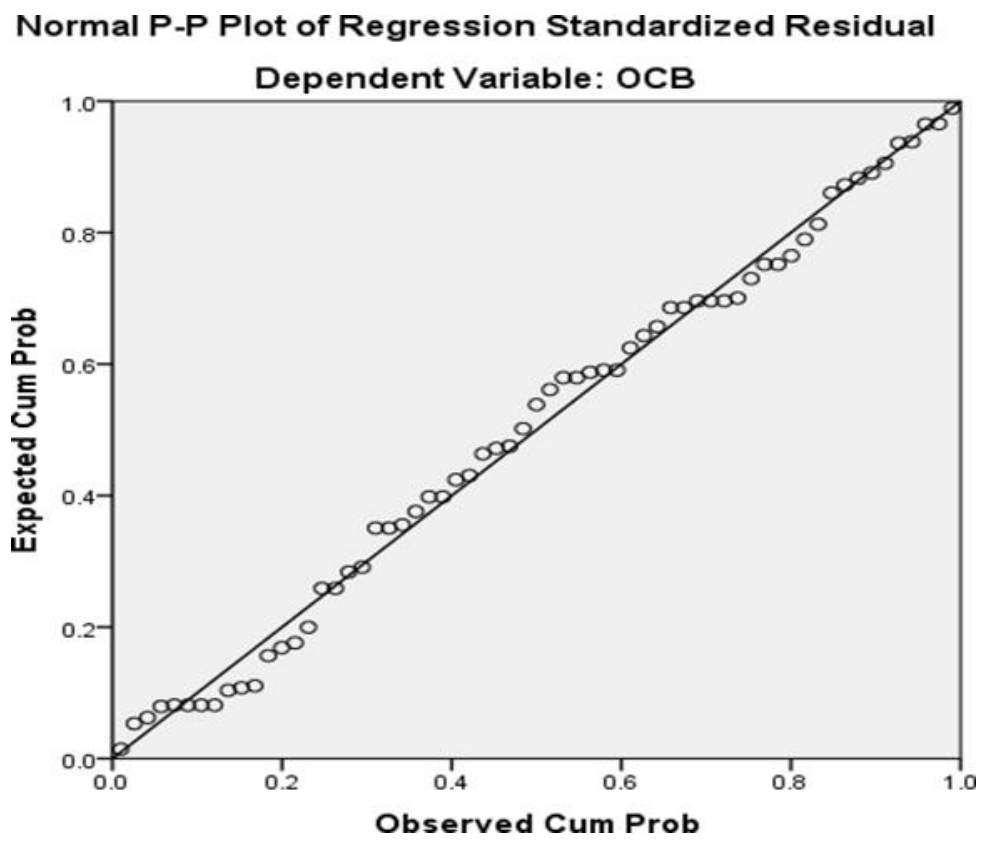

Gambar 5 Hasil Uji Normalitas Subtruktural II

Sumber: Data primer diolah, 2021

Berdasarkan gambar 4 dan 5 uji normalitas di atas terlihat bahwa data menyebar disekitar garis diagonal dan mengikuti arah garis diagonal. Maka model regresi memenuhi asumsi normalitas

\section{Uji Hipotesis}

Tabel 5. Hasil Uji t Sub Struktural I

\begin{tabular}{lccccc}
\hline \multirow{1}{*}{ Model } & \multicolumn{1}{c}{$\begin{array}{c}\text { Unstandardized } \\
\text { Coefficients }\end{array}$} & $\begin{array}{c}\text { Standardized } \\
\text { Coefficients }\end{array}$ & \multirow{2}{*}{$\mathbf{c}$} & \multirow{2}{*}{ Sig. } \\
\cline { 2 - 4 } & $\mathrm{B}$ & Std. Error & Beta & & \\
\hline $\begin{array}{l}\text { (Constatnt) } \\
\begin{array}{l}\text { Gaya } \\
\text { kepemimpinan }\end{array}\end{array}$ & 4.608 & 2,016 & & 2.286 & 0,026 \\
$\begin{array}{l}\text { Transformasional } \\
\text { Budaya }\end{array}$ & 0,229 & 0,084 & 0,310 & 2.720 & 0,009 \\
Organisasi & 0,411 & 0,093 & 0,504 & 4.425 & 0,000 \\
\hline
\end{tabular}

a. Dependent Variable : Komitmen Organisasi

Sumber : Data Primer Diolah, 2021

Dari tabel 5 diatas menunjukan bahwa :

1. Probabilitas signifikansi untuk variabel gaya kepemimpinan transformasional sebesar 0,009 $<0,05$ dan hasil perhitungan diperoleh angka $t$ hitung 2,720 $>\mathrm{t}$ tabel 2,000. Hasil ini menyatakan bahwa gaya kepemimpinan transformasional mempunyai pengaruh positif dan signifikan terhadap komitmen organisasi.

2. Probabilitas signifikansi untuk variabel budaya organisasi sebesar 0,000 $<0,05$ dan nilai hasil perhitungan diperoleh angka $\mathrm{t}$ hitung 4,425 $>\mathrm{t}$ tabel 2,000. Hal ini menyatakan bahwa budaya organisasi mempunyai pengaruh positif dan signifikan terhadap komitmen organisasi. 
Tabel 6. Hasil Uji t Sub Struktural II

\begin{tabular}{|c|c|c|c|c|c|}
\hline \multirow[t]{2}{*}{ Model } & \multicolumn{2}{|c|}{$\begin{array}{c}\text { Unstandardized } \\
\text { Coefficients }\end{array}$} & \multirow{2}{*}{$\begin{array}{r}\begin{array}{r}\text { Standardized } \\
\text { Coefficients }\end{array} \\
\text { Beta }\end{array}$} & \multirow[t]{2}{*}{$\mathbf{t}$} & \multirow[t]{2}{*}{ Sig. } \\
\hline & B & Std. Error & & & \\
\hline (Constatnt) & 7.837 & 2.742 & & 2.858 & .006 \\
\hline $\begin{array}{l}\text { Gaya kepemimpinan } \\
\text { Transformasional }\end{array}$ & 108 & .117 & .097 & .926 & .358 \\
\hline Budaya Organisasi & .378 & .140 & .309 & 2.710 & .009 \\
\hline Komitmen Organisasi & .746 & .168 & .497 & 4.430 & .000 \\
\hline
\end{tabular}

a. Dependent Variable : OCB

Sumber : Data Primer Diolah, 2021

Dari tabel 6 menunjukan bahwa:

1. Probabilitas signifikansi untuk variabel Gaya Kepemimpinan Transformasional sebesar 0,385 > 0,05 dan dari hasil perhitungan diperoleh angka $t$ hitung 0,926 $<\mathrm{t}$ tabel 2,001. Hasil ini menyatakan bahwa Gaya Kepemimpinan Transformasional mempunyai pengaruh negatif dan tidak signifikan terhadap variabel Organizational citizenship behavior.

2. Probabilitas signifikansi untuk variabel Budaya Organisasi sebesar 0,009 < 0,05 dan dari hasil perhitungan diperoleh angka $t$ hitung 2,710 $>\mathrm{t}$ tabel 2,001. Hasil ini menyatakan bahwa Budaya Organisasi mempunyai pengaruh positif dan signifikan terhadap variabel Organizational citizenship behavior.

3. Probabilitas signifikansi untuk variabel Komitmen Organisasi sebesar 0,000 < 0,05 dan dari hasil perhitungan diperoleh angka $t$ hitung 4,430 > t tabel 2,001. Hasil ini menyatakan bahwa Komitmen Organisasi mempunyai pengaruh positif dan tsignifikan terhadap variabel Organizational citizenship behavior.

\section{Koefisien Determinasi}

Tabel 7. Hasil Uji Koefisien Determinasi Sub Struktural I

\begin{tabular}{ccccc}
\hline Model & R & R Square & Adjusted R Square & $\begin{array}{c}\text { Std. Error of the } \\
\text { Estimate }\end{array}$ \\
\hline 1 & .744 & .553 & .538 & .993 \\
\hline
\end{tabular}

a. Predictors (Constant), Budaya Organisasi, Kepemimpinan Transformasional Sumber ; Data Primer Diolah, 2021

Berdasarkan tabel 7 di atas, hasil pengujian menunjukan bahwa nilai Adjusted $R^{2}$ persamaan I sebesar 0,538 artinya 53,8 \% variabel Komitmen Organisasi dapat dijelaskan oleh variabel gaya Kepemimpinan Transformasional dan Budaya Organisasi, sedangkan sisanya 46,2 \% dapat dijelaskan oleh variabel lain yang tidak ada dalam model penelitian ini.

Tabel 8. Hasil Uji Koefisien Determinasi Sub Struktural II

\begin{tabular}{ccccc}
\hline Model & R & R Square & Adjusted R Square & $\begin{array}{c}\text { Std. Error of the } \\
\text { Estimate }\end{array}$ \\
\hline 1 & .818 & .668 & .652 & 1.296 \\
\hline
\end{tabular}

Predictors (Constant), Budaya Organisasi, Gaya Kepemimpinan Transformasional, Komitmen Organisasi

Sumber : data Primer Diolah, 2021

Berdasarkan tabel 8 di atas, hasil pengujian menunjukan bahwa nilai Adjusted $\mathrm{R}^{2}$ persamaan I sebesar 0,652 artinya 65,2 \% variabel Organizational Citizenship Behavior dapat dijelaskan 
oleh variabel gaya Kepemimpinan Transformasional dan Budaya Organisasi dan Komitmen Organisasi sedangkan sisanya $34,8 \%$ dapat dijelaskan oleh variabel lain yang tidak ada dalam model penelitian ini.

\section{Analisis Korelasi}

Tabel 9. Hasil Uji Korelasi

\begin{tabular}{llrr}
\hline & & $\begin{array}{c}\text { Gaya Kepemimpnan } \\
\text { Transformasional }\end{array}$ & Budaya Organisasi \\
\hline & $\begin{array}{l}\text { Pearson- } \\
\text { Correlation }\end{array}$ & 1 & $.652^{* *}$ \\
Kepemimpinan & & & \\
Transformasional & Sig. (2-tailed) & 63 & .000 \\
& N & & 63 \\
& Pearson- & $.652^{* *}$ & 1 \\
Budaya & Correlation & & \\
Organisasi & Sig. (2-tailed) & .000 & 63 \\
\hline
\end{tabular}

** Correlation is significance at the 0.01 level (2-tailed)

Sumber : Data Primer Diolah, 2021

Berdasarkan tabel diatas, nilai korelasi Gaya Kepemimpnan Transformasional terhadap Budaya Organisasi sebesar 0,652 dan angka signifikansi sebesar 0,000 < 0,05, artinya antara variabel Gaya Kepemimpinan Transformasional dan Budaya Organisasi memiliki korelasi yang kuat dan signifkan.

\section{Uji Sobel}

\begin{tabular}{|c|c|c|c|c|}
\hline Input: & & Test statistic: & Std Error: & p-value: \\
\hline a 0.473 & Sobel test: & 4.52356918 & 0.10174024 & 0,00000608 \\
\hline b 0.973 & Aroian test: & 4.49620401 & 0.10235946 & 0.00000692 \\
\hline$s_{a} 0.073$ & Goodman test: & 4.55144016 & 0.10111723 & 0.00000533 \\
\hline Sb 0.154 & Reset all & & Calculate & \\
\hline
\end{tabular}

Data Primer Primer Diolah, 2021

\section{Gambar 6. Hasil Uji Sobel Sub Struktural I}

Berdasarkan gambar 6 hasil uji sobel struktural I menunjukan bahwa model gaya kepemimpinan transformasional melalui komitmen organisasi memiliki $p$-value atau signifikansi sebesar $0,000(\mathrm{p}<0,05)$ dan nilai sobel test statistic 4,523 lebih besar dari t tabel sebesar 2,000. Maka dapat disimpulkan bahwa komitmen organisasi dapat memediasi antara variabel gaya kepemimpinan transformasional dengan variabel organizational citizenship behavior. 


\begin{tabular}{|c|c|c|c|c|}
\hline Input & & Teststatistic & Std Error: & p-value \\
\hline a 0.576 & Sobel test & 4.21806058 & 0.10897141 & 0.00002464 \\
\hline b 0.798 & Aroian test & 4.19368594 & 0.10960477 & 0.00002745 \\
\hline$s_{a} 0.074$ & Goodman test & 4.24286523 & 0.10833434 & 0.00002207 \\
\hline$s_{b} 0.159$ & Reset all & & Calculate & \\
\hline
\end{tabular}

Data Primer Primer Diolah, 2021

Gambar 7. Hasil Uji Sobel Sub Struktural II

Berdasarkan gambar 7, hasil uji sobel struktural II menunjukan bahwa model budaya organisasi melalui komitmen organisasi memiliki p-value atau signifikansi sebesar $0,000(\mathrm{p}<$ $0,05)$ dan nilai sobel test statistic 4,218 lebih besar dari $t$ tabel sebesar 2,000. Maka dapat disimpulkan bahwa komitmen organisasi dapat memediasi antara variabel budaya organisasi dengan variabel organizational citizenship behavior.

\section{Pembahasan}

Pengujian hipotesis pertama dilakukan untuk mengetahui pengaruh gaya kepemimpinan transformasional terhadap komitmen organisasi. Berdasarkan hasil uji t diperoleh $\mathrm{t}$ hitung sebesar 2,720 > t tabel 2,000 dengan tingkat signifikansi sebesar 0,009>0,05 hal ini menunjukan bahwa gaya kepemimpinan transformasional mempunyai pengaruh positif dan signifikan terhadap komitmen organisasi. Artinya, semakin baik gaya kepemimpinan transformasional yang ditunjukan oleh pimpinan kerja maka akan semakin tinggi pula komitmen para pegawai terhadap organisasi. Hasil penelitian ini mendukung penelitian yang dilakukan oleh Amelia Rahmi dan Mulyadi (2018) terhadap karyawan PT. PLN Banda Aceh yang menyatakan bahwa terdapat pengaruh positif dan signifikan antara gaya kepemimpinan transformasional dan komitmen organisasi. Implikasi manajerial dari penelitian ini adalah Kepala UPTD sebagai pimpinan kerja di UPTD menjadi role model bagi bawahannya dalam bersikap, bertindak, dan melaksanakan tanggungjawab pekerjaan, sehingga harus mampu menjaga sikap dan tindaknnya dikarenakan hal tersebut dapat mempengaruhi bawahannya.

Kepala UPTD sebagai pimpinan kerja harus mampu membangun komunikasi yang baik dengan bawahannya, adaptif dan reaktif terhadap setiap keluhan, kendala, dan masukan dari bawahannya terkait pekerjaan di lapangan. Pimpinan kerja juga secara rutin dalam setiap kesempatan mengingatkan dan memotivasi para bawahaannya untuk selalu mengedepankan visi dan misi dari organisasi. Dengan begitu para pegawai akan bekerja dengan penuh tanggungjawab, komitmen, serta mampu mengedepankan visi dan misi organisasi.

Berdasarkan analisis dan pembahasan terbukti bahwa budaya organisasi berpengaruh positif dan signifikan terhadap komitmen organisasi karena diperoleh nilai signifikansi sebesar 0,000 $<0,05$ dan nilai hasil perhitungan diperoleh $\mathrm{t}$ hitung 4,425 $>\mathrm{t}$ tabel 2,000. Semakin baik budaya yang diterapkan didalam organisasi maka semakin baik pula rasa komitmen yang dimiliki oleh para pegawai terhadap organisasi. Kultur organisasi yang mengedepankan nlai kekeluargaan, profesionalisme, dan etos kerja akan membentuk para 
pegawai yang mempunyai rasa tanggungjawab, loyalitas, dan komitmen yang baik terhadap organisasi.

Dimensi dari budaya organisasi salah satunya adalah people orientation, yaitu setiap eputusan atau kebijakan yang diambil atau dibuat oleh organisasi akan berorientasi terhadap orangorang yang ada di dalam organisasi terkait dampak dari kebijakan tersebut. Budaya organisasi semacam ini tent akan membuat para anggotanya merasa dihargai dan dilibatkan dalam setiap kebijakan organisasi, sehingga timbal baliknya mereka juga akan merasa mempunyai ikatan dengan organisasi. Hasil penelitian ini sesuai dengan penelitian Tiara Putri Usmany, dkk (2016) yang juga menyatakan terdapat pengaruh signifikan dan positif antara budaya organisasi terhadap komitmen organisasi.

Berdasarkan dari hasil uji $\mathrm{t}$ diperoleh $\mathrm{t}$ hitung sebesar 0,385 >0,05 dan hasil dari perhitungan diperoleh angka $\mathrm{t}$ hitung 0,926 < $\mathrm{t}$ tabel 2,001. Artinya bahwa gaya kepemimpinan transformasional tidak mempunyai pengaruh positif dan tidak signifikan terhadap variabel organizational citizenship behavior. Hasil penelitian ini tidak sesuai dengan peneltian yang dilakukan oleh I Made Bagus Arya dan I Gusti Made Suwandana (2017) terhadap karywan PT. Lila Buana yang menyatakan bahwa gaya kepemimpinan transformasional berpengaruh positif dan signifikan terhadap organizational citizenship behavior. Hasil penelitian ini lebih sesuai dengan penelitian yang dilakukan Yustina Eko Purwaningsih dan Lie Liana (2018) yang hasilnya sama-sama menyatakan bahwa gaya kepemimpinan transformasional tidak berpengaruh terhadap organizational citizenship behavior.

Berdasarkan hasil uji $\mathrm{t}$ bahwasanya probabilitas signifikansi untuk variabel budaya organisasi sebesar 0,009, 0,05 dan dari hasil perhitungan diperoleh angka $t$ hitung sebesar $2,710>t$ tabel 2,001. Artinya bahwa budaya organisasi mempunyai pengaruh positif dan signifikan terhadap variabel organizational citizenship behavior. Semakin baik budaya yang diterapkan oleh organisasi, maka semakin baik pula perilaku OCB dari para anggota organisasi. Hasil ini juga sependapat dengan penelitian yang sudah dilakukan oleh I Putu Satya Nugraha dan I Gusti ayu adnyani (2018) terhadap pegawai Setda Kota Denpasar.

Sebagai organisasi sektor pelayanan publik, UPTD Pengelolaan Air Limbah Dan Sampah Wilayah Timur sudah seharusnya menerapkan dan menjalankan nilai-nilai atau kebiasaaan yang baik sebagai acuan bagi para pegawainya dalam bekerja., seperti berfikir kreatif dan inovatif, kerja cermat dan mendetail, berorientasi pada hasil, serta melakukan aktivitas kerja dengan mengutamakan kinerja tim. Budaya-budaya tersebut akan membentuk karakter kerja yang peduli terhadap hasil kerja, rekan kerja, serta organisasi. Organisasi juga harus mempertimbangkan dampak dari keputusan dan kebijakannya terhadap anggotanya.

Berdasarkan analisis dan pembahasan terbukti bahwa komitmen organisasi berpengaruh positif dan signifikan terhadap organizational citizenship behavior karena diperoleh nilai signifikansi sebesar 0,000 $<0,05$ dan dari hasil perhitungan diperoleh angka t hitung sebesar 4,430 . $\mathrm{t}$ tabel 2,001. Hasil ini artinya semakin tinggi komitmen terhadap organisasi dari para pegawai maka organizational citizenship behavior juga akan meningkat. Hasil penelitian ini juga sesuai dengan hasil penelitian yang dilakukan oleh Indhira Pratiwi (2013) yang juga menyatakan bahwa, komitmen organisasional berpengaruh positif dan signifikan terhadap OCB.

Komitmen muncul dikarenakan adanya rasa keterikatan secara emosional, rasa nyaman, dan juga kebutuhan serta ketergantungan terhadap organisasi. Untuk mencuptakan rasa 
tersebut, tentunya oragnisasi harus mampu merespon setiap keluhan, kendala dan masukan dari para anggotanya, mampu menjamin keselamatan kerja dan kesejahteraan anggotanya dalam setiap keputusan atau kebijakan yang diambil.

Berdasarkan analisis dan perhitungan yang dilakukan peneliti yang dilakukan dengan cara uji sobel ( Sobel test) menyatakan bahwa komitmen organisasi dapat memediasi antara variabel gaya kepemimpinan transformasional dengan variabel organizational citizenship behavior karena diperoleh nilai signifikansi sebesar 0,000 $<0,05$ dan nilai sobel test statistic 4,523 lebih besar dari t tabel sebesar 2,000. Hasil penelitian ini sesuai dengan penelitian yang sudah dilakukan oleh Yustina Eko Purwaningsih dan Lie Liana pada tahun 2015.

Sikap dan perilku pimpinan kerja yang menjadi role model serta dapat mengayomi para bawahannya dapat memunculkan rasa nyaman dan rasa komit terhadap organisasi. Para pegawai yang mempunyai komitmen besar terhadap organisasi tentunya akan memberikan sesuatu yang melebihi ekspetasi dari organisasi.

Berdasarkan analisis dan perhitungan yang dilakukan peneliti yang dilakukan dengan cara uji sobel ( Sobel test) menyatakan bahwa komitmen organisasi dapat memediasi antara variabel budaya organisasi dengan variabel organizational citizenship behavior karena diperoleh nilai signifikansi sebesar 0,000 $<0,05$ dan nilai sobel test statistic 4,218 lebih besar dari $\mathrm{t}$ tabel sebesar 2,000. Hasil penelitian ini juga sesuai dengan penelitian yag sudah dilakukan oleh Indhira Pratiwi pada tahun 2013 yang juga menyatakan bahwa komitmen organisasi terbukti memediasi hubungan antara budaya organisasi dengan organizational citizenship behavior.

Nilai-nilai budaya bagi organisasi sangatlah penting. Budaya organisasi akan membentuk karakter kerja bagi para anggotanya. Contoh halnya dalam melakukan pekerjaan, organisasi yang membiasakan anggotanya untuk mengutamakan kerjasama tim dalam setiap penyeleaian pekerjaan secara tidak langsung akan menanamkan nilai-nilai kepedulian bukan hanya terhadap reka kerja tetapi juga terhadap organisasi.

\section{Penutup dan Saran}

Berdasarkan penelitian tentang pengaruh gaya kepemimpinan transformasional dan budaya organisasi terhadap organizational citizenship behavior melalui komitmen organisasi sebagai variabel intervening pada UPTD Pengelolaan Air Limbah dan Sampah Wilayah Timur Dinas Perkim LH Kabupaten Kebumen, maka penulis dapat menarik kesimpulan sebagai berikut :

1) Gaya kepemimpinan transformasional berpengaruh positif dan signifikan terhadap komitmen organisasi pada pegawai UPTD Pengelolaan Air Limbah dan Sampah Wilayah Timur Dinas Perkim LH Kabupaten Kebumen.

2) Budaya Organisasi berpengaruh positif dan signifikan terhadap komitmen organisasi pada pegawai UPTD Pengelolaan Air Limbah dan Sampah Wilayah Timur Dinas Perkim LH Kabupaten Kebumen.

3) Gaya kepemimpinan transformasional tidak mempunyai pengaruh terhadap organizational citizenship behavior pada pegawai UPTD Pengelolaan Air Limbah dan Sampah Wilayah Timur Dinas Perkim LH Kabupaten Kebumen. 
4) Budaya organisasi berpengaruh positif dan signifikan terhadap organizational citizenship behavior pada pegawai UPTD Pengelolaan Air Limbah dan Sampah Wilayah Timur Dinas Perkim LH Kabupaten Kebumen.

5) Komitmen organisasi berpengaruh positif dan signifikan terhadap organizational citizenship behavior pada pegawai UPTD Pengelolaan Air Limbah dan Sampah Wilayah Timur Dinas Perkim LH Kabupaten Kebumen.

6) Komitmen organisasi terbukti mampu memediasi hubungan antara gaya kepemimpinan transformasional dengan organizational citizenship behaviorpada pegawai UPTD Pengelolaan Air Limbah dan Sampah Wilayah Timur Dinas Perkim LH Kabupaten Kebumen.

7) Komitmen organisasi terbukti mampu memediasi hubungan antara budaya dengan organizational citizenship behavior pada pegawai UPTD Pengelolaan Air Limbah dan Sampah Wilayah Timur Dinas Perkim LH Kabupaten Kebumen.

Penelitian ini belum dapat mengungkapkan secara keseluruhan faktor yang mempengaruhi perilaku OCB Pegawai UPTD Pengelolaan Air Limbah dan Sampah Wilayah Timur Dinas Perkim Lh Kabupaten Kebumen, penelitian ini hanya terbatas pada faktor gaya kepemimpinan transformasional, budaya organisasi, dan komitmen organisasi. Untuk penelitian selanjutnya juga diharapkan untuk memperluas ruang lingkup wilayah penelitian dan lokasi penelitian, sehingga hasil penelitian dapat diimplementasikan secara umum.

\section{Referensi}

Allen, N. J., \& Meyer, J. P. (1990). The measurement and antecedents of affective, continuance and normative commitment to the organization. Journal of occupational psychology, 63(1), $1-18$.

Amir, T. (2017). Perilaku Organisasi. Edisi Pertama. Jakarta: Kencana.

Badeni, B. (2014). Kepemimpinan dan Perilaku Organisasi. Bandung: Alfabeta.

Darto, M. (2014). Peran Organizational Citizenship Behavior (OCB) Dalam Peningkatan Kinerja Individu Di Sektor Publik: Sebuah Analisis Teoritis Dan Empiris (the Role of Organizational Citizenship Behavior (OCB) in the Individual Performance Improvement in the Public Sector. Jurnal Borneo Administrator, 10(1), 10-14.

Ghozali, I. (2009). Aplikasi Analisis Multivariate Dengan Program SPSS. Semarang: Universitas Diponegoro.

Gunawan, R. (2016). Pengaruh Kepemimpinan Transformasional Terhadap Organizational Citizenship Behavior (OCB) Pada PT First Marchinery Tradeco Cabang Surabaya. Agora, 4(1), 60-66.

Hadi, N. (2011). Corporate Social Responbilty. Yogyakarta: Graha Ilmu.

Lubis, Y., Hermanto, B., \& Edison, E. (2018). Manajemen Dan Riset sumber Daya Manusia. Bandung: Alfabeta.

Luthans, F. (2006). Perilaku Organisasi. Edisi Sepuluh. Yogyakarta: Andi.

Nawawi, H. (2016). Kepemimpinan Mengefektifkan Organisasi. Yogyakarta: Gadjah Mada University Press. 
Nugraha, I. P. S., \& Adnyani, I. G. A. D. (2018). budaya organisasi, komitmen organaisasi, dan kompetensi terhadap organizational citizenship behaviour pada setda kota denpasar. E-Jurnal Manajemen, 7(1), 1-28.

Oemar, Y. (2013). Pengaruh Budaya Organisasi, Kemampuan Kerja dan Komitmen Organisasi terhadap Organizational Citizenhsip Behavior (OCB) Pegawai pada BAPPEDA Kota Pekanbaru. Jurnal Aplikasi Manajemen, 11(1), 65-76.

Organ, D.W., Podsakof, P.M., \&Mackenzie, S.B. (2006). Organizational Citizhenship Behavior: its nature, antecdents, and consequences. USA: Sage Publications.

Permana, A. D., \& Sriathi, A. A. A. (2017). Pengaruh Kepemimpinan Transformasional, Kepuasan Kerja dan Komitmen Organisasional Terhadap Organizational Citizenship Behavior Guru. E-Jurnal Manajemen, 6(8), 4185 - 4213.

Priansa, D. J. (2018). Perencanaan dan Pengembangan Sumber Daya Manusia. Bandung: Alfabeta.

Rahmi, A., \& Mulyadi, M. (2019). Pengaruh Keterlibatan Karyawan, Budaya Organisasi dan Kepemimpinan Transformasional terhadap Komitmen Organisasional Karyawan pada PT. PLN Banda Aceh. Jurnal Ilman: Jurnal Ilmu Manajemen, 6(1), 68-76.

Robbins, S. P. (2006). Perilaku Organisasi.Edisi Kesepuluh. Jakarta: Indeks Kelompok Gramedia.

Robbins, S. P., \& Judge, T. A. (2008). Perilaku Organisasi, Edisi Kedua Belas, Jakarta: Salemba Empat.

Siagian, D., \& Sugiarto, S. (2006). Metode Statistika. Jakarta: Gramedia Pustaka Utama.

Subawa, I. M. B. A., \& Suwandana, I. G. M. (2017). Pengaruh Kepemimpinan Transformasional, Kepuasan Kerja, dan Komitmen Organisasinal Terhadap Organizational Citizenship Behavior. Jurnal Manajemen Unud, 6(9), 4772-4799.

Sugiyono, S. (2005). Metode Penelitian Pendidikan Pendekatan Kuantitatif, Kualitatif, dan R\&D. Bandung: Alfabeta.

Sutrisno, E. (2010). Budaya Organisasi. Jakarta: Kencana.

Suwatno, D. J. (2018). Manajemen SDM Dalam Organisasi Publik dan Bisnis. Bandung: Alfabet.

Suzana, A. (2017). Pengaruh Organizational Citizenship Behavior (OCB) terhadap kinerja karyawan (studi di: PT. Taspen (Persero) kantor cabang Cirebon). LOGIKA Jurnal Ilmiah Lemlit Unswagati Cirebon, 19(1), 42-50.

Titisari, P. (2014). Peranan Organizational Citizenship Behavior (OCB) Dalam Meningkatkan Kinerja Karyawan. Jakarta: Mitra Wacana Media.

Usmany, T. P., Hamid, D., \& Utami, H. N. (2016). Pengaruh Budaya Organisasi Terhadap Komitmen Organisasional dan Kinerja Karyawan (Studi pada Karyawan Pabrik Gondorukem dan Terpentin Sukun Perum Perhutani Kesatuan Bisnis Mandiri Industri Gondorukem dan Terpentin II, Ponorogo). Jurnal Administrasi Bisnis, 37(2), 38-44.

Wahjono, I. S. (2010). Perilaku Organisasi. Yogyakarta: Graha Ilmu. 
Jurnal Ilmiah Mahasiswa Manajemen, Bisnis dan Akuntansi 3(3) Juni 2021

Williams, L. J., \& Anderson, S. E. (1991). Job satisfaction and organizational commitment as predictors of organizational citizenship and in-role behaviors. Journal of management, 17(3), 601-617. 